\title{
Bachelor of Social Work
}

National Cancer Institute

\section{Source}

National Cancer Institute. Bachelor of Social Work. NCI Thesaurus. Code C71353.

A bachelor's degree awarded to someone who has successfully completed

undergraduate studies in psychosocial evaluation and intervention, including therapy, to effect a change in the feelings, attitudes and behavior of a client, whether an individual, group or community. 